largely of mica-schists and clay-slates. In another memoir just published he furnishes additional information regarding the succession of these rocks. The old or fundamental (Archæan) rocks composed of gneiss, granite, \&c., are overlain by thick masses of reddish sandstones, followed by quartzites and limestones, over which come Augen-gneiss, hornblende-schist, mica-schist, \&c. This order of sequence, which is shown in numerous natural sections, will be at once recognised as that which Murchison first showed to be the stratigraphical succession in the north-west of Scotland. It is interesting to find that the parallelism which was traced many years ago between the structure of the Highlands of Scotland and the uplands of Scandinavia continues to be confirmed by the more detailed surveys of recent years.

\section{OBSERVATION OF THE GREAT COMET OF 1882}

(Communicated by Vice-Admiral Rowan, Superintendent U.S. Naval Observatory)

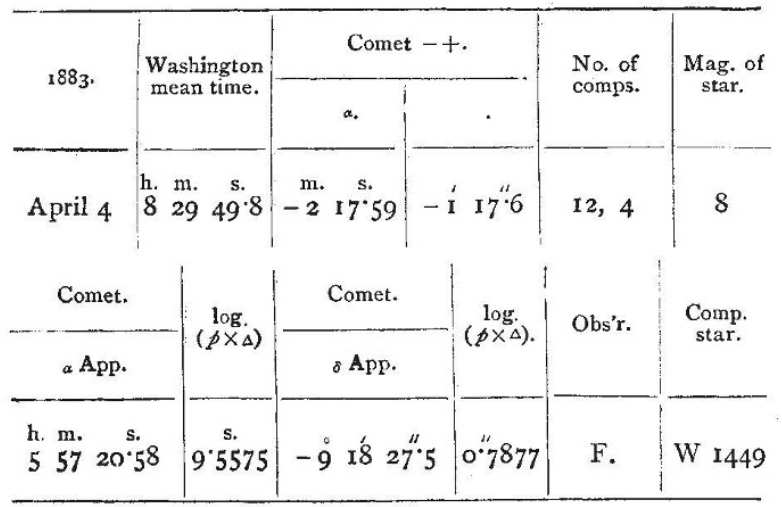

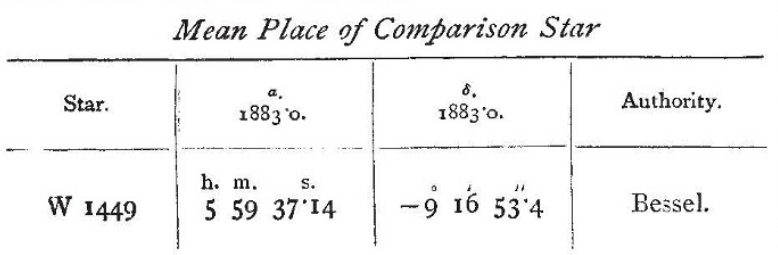

\begin{tabular}{|c|c|c|c|}
\hline \multirow{2}{*}{ Date. } & Obs. & Comp. & \multirow{2}{*}{ Eph. } \\
\hline & $\Delta a_{a}$ & $\Delta \delta$. & \\
\hline 1825. & $\begin{array}{c}\text { s. } \\
+4.06\end{array}$ & $+I_{4}^{\prime \prime}$ & $\begin{array}{l}\text { Nature, vol. xxvii. p. } 226, \\
\text { and } A \text { st. Reg. No. } 243, \text { p. } 72 .\end{array}$ \\
\hline
\end{tabular}

This observation was made with the 26 -inch equatorial, and compared with the following of three bright points in the nucleus. If we had compared the middle point of the nucleus with the comet, the corrections would have been $\quad \Delta a=+\mathrm{I}^{\mathrm{s} \cdot 3} \quad \Delta \delta=+\mathrm{o}^{\prime} \cdot 3$.

E. FRISBY,

Washington, April $6 \quad$ Prof. Math., U.S.N.

\section{ANTHROPOLOG $Y^{1}$}

I.

THE invitation to lecture on anthropology with which I have been honoured gives me freedom to speak both of the races of mankind zoologically, and also of the thoughts, arts, and habits which form their civilisation.

I Two lectures on "Anthropology," delivered on February $\mathrm{r}_{5}$ and $2 \mathrm{I}$ at the University Museum, Oxford, by E. B. Tylor, D.C.L., F.R.S.
It is on the development of civilisation that I especially wish to dwell, a subject of direct interest always and to all, and the more opportune now that the practical question of the instalment of a Museum of Civilisation in Oxford is under discussion. Still, man's bodily and mental history so act and interact on each other that it is well to carry on their study together. Both depend on the great principle of adaptive change, where rise in organisation gives fuller and freer existence, till "correspondence with the énvironment" fixes a more or less permanent state, or suppression or disuse brings on degeneration. These are processes systematised in the theories of development or evolution which have of late years become predominant, and which seek to account for the change of plants and animals on the earth by modified descent, and of mental and moral phenomena by modified sequence. There is a consideration I wish to bring prominently forward, as not having had the attention it deserves. It is that these processes of development, or evolution, or transformism were long ago recognised to no small extent by ethnologists. Thus Prichard, the leader of the monogenist school forty years ago, brought forward evidence for the derivation of the races of mankind from one original ancestral pair, whom he considered to have been negroes, whose descendants more or less varying by the operation of natural causes became modified or transformed into the various races adapted for life in the various climates of the earth. But this, so far as it goes, is the very theory of development or modified descent. Any ethnologist who argues on natural grounds "that all the races of man are descended from a single primitive stock," is an evolutionist within these limits; in fact these words are quoted not from Prichard or Quatrefages, but from Darwin. Within the last generation the science of man has had new evidence and argument brought within its range. The discovery that men were already making rude flint implements in the Quaternary period, when the contours of hill and valley were quite other than during the few thousand years known to chronology, has made a new scientific departure, placing primæval man in the hands of the geologists, who are now discussing whether he even existed in the yet more vastly remote Tertiary period. A yet greater move has been made by Darwin's systematic application of the principles of variation of breeds or races to account for the transitions between species or genera. How these have become transformed in the course of geological time is seen in Huxley's plate of the bones of the four-toed Orohippus, followed by the three-toed Miohippus and Hipparion, and this again by the horse of the present day. Zoologists thus enabled to reconstruct ideally the ancestry of the horse, are hopeful some day to discover likewise the fossil pedigree of the rider.

Thus it is plain why the new lines of biological research, whether into the general causes of variation in animals, or into the origin of the human species from a succession of lower mammalian forms, have not checked but stimulated the research which relates to man as man. Anthropologists do not feel as if their science had been plucked up by the roots and planted somewhere else; it is growing where it was, only cultivated higher than in old times. What substantial progress has been made of late years is well seen in the difficult department of craniology. That there really is something in the shape of a skull will be admitted when one compares the two before us on the table, types which illustrate an interesting point in the early history of our own country. The narrower skull belonged to one of that dolichocephalic Stone Age population whose remains were buried in the long-barrows on our downs. The broader skull belonged to one of the brachycephalic men of the later round-barrows. In the work of Greenwell and Rolleston will be found the anatomical comparison of these skull-types, and the evidence that the earlier tribes were not exterminated by the later 
invaders of the land, but that the two races lived and were buried together, and by intermarrying gave rise to a mixed population. What these early long-headed people were called, or what language they spoke, is still unknown. It is they to whom, on the strength of certain passages in classic authors, the name of Iberian has sometimes been given, and they have been identified with the Basques. But no absolute correspondence has been made out between them and any race past or present in Spain, so that Prof. Rolleston was wise in preferring to call the men of the English long-barrows by the local name of Silurians, and to rely on skulls for defining the type, and the burial-places for marking the state of civilisation, of an ancient race who thus take a well-marked place in the history of our land, but of whom we may possibly never learn much more.

The mixture of races which has gone on for ages in Europe makes European craniology a study of extreme difficulty, but to see its clearest results we must look to races long isolated and intermarrying till their skulls become almost uniform. How such a type will characterise a genuine race has been shown by Prof. Flower in describing the skulls from the burial-caverns of the Kai Colo, the mountain people who appear to have been the original inhabitants of Fiji. These mountaineers, whose distinction it is to have had the narrowest skulls of any known race, are representatives of the frizz-haired blacks so widely spread in the island groups now called after them Melanesian. But the ordinary Fijian population, who have lately been incorporated in the British Empire, are not exactly Melanesians, nor are they Polynesians like the brown Samoans and Tongans of the islands to the eastward. It appears that these black and brown islanders have intermixed and become the joint parents of the present Fijian population. This is perfectly shown by their skulls, whose cephalic index of breadth (7I) is intermediate between those of the two parent races, the ancient Melanesian mountaineers (66) and the Polynesians (83). Not only does the cephalic index of length and breadth follow this rule, but it proves true in the same way of the index of height, and of other measurements of jaw, eye, and nose, which almost absolutely follow the same rule of the mixed race between the two parent races. The gradation is so marked, that in the Fijian islands nearest the Polynesian islands the skullmeasurements come nearest to the Polynesian type. It is I think the first time that anthropology has made so close an approach to mathematical accuracy in its inferences, and it must be admitted that when arithmetical rule thus finds its way into a descriptive science, the study is becoming serious. Let us now see what comparative philology has to say to this Fijian question. Every student who opens a Fijian grammar is apt to say, Here is a Polynesian language, like Maori or Tongan; the map shows in the names of the islands plain Polynesian words that a New Zealander would understand, such as vamua $=$ land, lima = five ; the Fijian not only has the familiar Polynesian tabu = sacred, but he can attach the Polynesian causative prefix waka to it and make the verb wakatabu = to tabu a thing or make it sacred. Yet this student, as he examines and aralyses more deeply, is driven to admit that Fijian must not be catalogued among the Polynesian languages; indeed it seems as though the root and heart of it must be classed as Melanesian, belonging to the black not the brown race; nevertheless the black language has absorbed not only the words but the character of the brown language into an intimacy and depth of mixture hardly anywhere equalled. Prof. Max Müller, in the lectures which near a quarter of a century ago made a new era in the science of language in England, was careful to give the much-needed caution not to trust too much to language in settling questions of race. Here, however, is an example how language, in cases when it is possible to get its bearing clearly into view, may tell its story in perfect accordance with anatomy. The blenderi parentage of the Fijians is heard in their speech as it is seen in their faces.

Not less important as a distinctive mark of race is the hair. A single hair now enables the anthropologist to judge in what division of the human species he will class its owner; there is no mistaking a Chinese for a European, or either for an African. The cross-section of this single hair, examined microscopically by Pruner's method, shows it circular, or oval, or reniform; its follicle-curvature may be estimated by the эverage diameter of the curls as proposed by Moseley; its colouring matter may be estimated by Sorby's method. There has been even a systematic classification of man published by Dr. W. Muiller, of the Novara Expedition, which is primarily arranged according to hair, in straight-haired races, curlyhaired races, \&c., with a secondary division according to language. Though we cannot regard such a system as good, the wonder is that it should answer so well as it does; indeed nothing could prove more clearly how real race-distinctions are, that a single bodily character should form a basis for rationally mapping out the divisions of mankind.

It is now well understood that the causes of race-colour are not so simple as Hippocrates thought when be described the nomad Scythians as burned tawny by the cold. But the study of anthropologists is still to notice the characters which mark off the white, yellow, brown, and black races, and to connect therewith the effects of climate and mode of life. The analogy of fair or blond skin to partial albinism is striking, and possibly points to some similarity of cause. A book has even been written by Dr. Poesche to explain thus the formation of the white race. The fair whites, according to this author, are semialbinos, whose ancestors were once a browner race in Northern Asia, but turned fair in the swampy regions of the Dneiper, where men and beasts grow light in colour, horses grey, the leaves of the trees pale, and all nature dull and colourless. Such imaginative speculation is an example to be avoided by anthropologists, and yet the resemblance of blond to semi-albino skin is one which when worked out by careful observation will doubtless lead to discovery. A yet more striking case of the morbid appearance of race-character is seen in "bronzed skin," a symptom of "Addison's disease." Here the resemblance to mulatto complexion is so marked that in the reports of cases it is quite a regular thing for the physician to mention that he asked the patient if he was of negro blood. Even that well-known negro feature, the comparatively light tint of palms and soles, was there, though there was wanting one of the points which anthropologists look to when they suspect negro ancestry, namely, the yellowness of what we characteristically call the "white" of the eye. It is not however on merely superficial comparison that this analogy depends. Anthropologists unfortunately do not always hear of medical work bearing on their studies, and it is but lately that I learnt from Dr. Wilson Fox that an interesting microscopic section of "bronzed skin" was published years ago by Mr. Hutchinson in the Pathological Transactions. All who compare this with Kölliker's section of normal negro skin must admit the extraordinary similarity of coloration, in the manner in which the deep brown pigment cells and grains line the surface of the papillæ of the dermis or true skin. I shall not be charged with propounding here a theory that black men are white men thus transformed, for, indeed, one incident of the obscure disease in question is that the patient always dies. The importance of the comparison lies in its bridging over the physiological differences of race, by showing that morbid action may bring about in one race results more or less analogous to the normal type in another.

The differences in race-characters among mankind are 
far better known than are the causes which bring them about. Yet it would be too much to say that we do not know how to alter the type of a race. For instance, s'ature is one point of race-type, and we know by actual experience that if a population of the Yorkshire dales is brought in to live in factory towns, in two generations they are found to be $I \frac{1}{2}$ inch lower in average stature than their countrybred kinsfolk. Indeed, it appears from Beddoe's careful statistics that the stature of the London population is gradually lessening. The great means of change of race-type is acclimatisation. Dr. Acland has here called attention to the interesting problem presented by the tribes of "unhealthy districts" in India, who live where tribes allied to them in race and language cannot exist, nor can they themselves go back, without falling sick, to the plains whence their ancestors came. That this acslimatisation affects the secretions and hue of skin is certain, but this topic is one on which only a pathologist can speak with any authority. If, however, we look at the map of the world, it is as evident to us as it was to Hippocrates that race depends in some measure on climite and mode of life. The leading fact is the lie of the negro type along the equator, as contrasted with the xanthous or blond type in the northern temperate zone. The permanence of the races of mankind, such as the Egyptian, which the polygenist school interpreted as evidence that it was a species by itself, is better explained in Draper's words that "its durability arises from its perfect correspondence with its environment." It is only when moved into different conditions that a race has in change into harmony with these new conditions.

Turning now from the development of races to the levelopment of their civilisation, the task is made easy by the help of evidence geological in its character. The presence of stone implements in every part of the world proves that they were once used there, and that the races using them had no metal. But now stone implements are distinguished into the ruder Palæolithic and the more finished Neolithic. The ruder, discovered in gravels of great antiquity with the remains of the mammoth and other prehistoric animals in Europe, must therefore be the older, but this also seems to be evident from their very nature. If men with bronze weapons had no more bronze, they might very likely fall back on the best substitute they could make, the-hard, ground stone celt; but it seems against all reason that those who knew how to yrind a hatchet on a whetstone should have lost that simple if laborious art. Thus culture confirms what geology teaches, that the rude stage of man's history to which the rude implement belongs is also the earlier stage, and the higher polished implement comes later. It comes on indeed into modern times, for the general extinction of the Stone Age in Australia or America only dates from this century, and even at this day in Australia the traveller learns from the blackfellow how the rude chipped axe-flake is to be gummed to the helve, or the white hunter sits down in California to be shown how to chip out the neat obsidian arrowhead with the point of deerhorn. In a few ages after metal has come in, the new people forgets that the old people ever used such things. Thus it comes to pass that, across the world from Iceland to Japan, stone hatchets and arrowheads dug up in the ground are supposed to be the material weapons hurled or shot from the sky, whose flight is seen in the lightning-flash Such "thunderbolts" have for ages been valued for magical power, especially the appropriate uses of guarding against fire and inflammatory disease ; Pythagoras was purified with a thunderbolt, and stone arrowheads form the centre-pieces of some of the most beautiful of Etruscan gold necklaces. Even a bronze implement may be taken for a thunderbolt by those who have forgotten its nature; the bronze celt here produced was dug up in Wiltshire, where the lightning had struck an oak, and it has since for many years been the magical thunderbolt of a west country hamlet.

Even where the old use dwindles and changes, survival in altered shape may keep on the old ideas : our own life is full of survivals. In ceremonial processions we still see the javelins and halberds belonging to war before gunpowder, and though the mace no longer smashes helmets, it remains as an emblem of power and dignity. Our books are ornamented with gilt lines which once represented the real cross-binding; as in perhaps the most modern of survivals, where the tape which bound the registered letter has dwindled to blue cross-lines printed on the envelope. Language is full of such records of the past; as when one hears people declare they do not care a groat, a doit, or a rap, when they would not recognise if they saw them these ol 1-fashioned varieties of small change. Thus what with the lasting on of old things among outlying peoples, and what with the survival of them among the civilised world, the thread of connection is by no means lost from remotest times. For my own part, when I look at the utter likeness of the working processes of the mind among the races most different in skin, and when I see the resemblance of rude ideas and customs throughout the inhabited world, I cannot but think that much of the thought and habit of mankind not only goes back to the remote Palæolithic age, but that it may be older than the divisions of race which separate us from the Chinese or the Negro. Let me offer examples of a mental state yet surviving which may have its origin in the very childbood of mankind. Uneducated men, from the savage to the peasant, remain more or less in that childlike state of mind where the distinction between dreams and real events is not yet perfectly made ; dreams seem to be visits from phantom souls of others coming to the sleeper, or excursions of his own phantom or soul away from his body. The state of primitive thought in which psychology thus grows out of the phenomena of dreams has perhaps never been better displayed than in a recent account by Mr. Im Thurn in the Journal of the Anthropoloyical Institute of his Indian boatmen in British Guiana. One morning a young Macusi was so enraged against him that he refused to stir, declaring that his master, without consideration for his weak health, had taken him out in the night and made him drag the canoe up a series of cataracts. Notbing would persuade him that it was only a dream, and it was long before he was sufficiently pacified to throw himself sullenly into the bottom of the canoe. Food was scarce, and such dreams in consequence frequent, so that morning after morning the Indians were complaining that some man (whom they named) had visited their hammocks in the night, and beaten or otherwise maltreated them. In the middle of one night $\mathrm{Mr}$. Im Thurn was awakened by his headman, an Arawak named Sam, who addressed him in these bewildering words: "George speak me very bad, boss; you cut his bits." On explanation, it proved that Sam had dreamt that George, one of the men under him, had spoken impudently to him, and had come at once to his master to demand that the culprit should be punished by cutting so many bits (i.e. fourpenny pieces) off his wages.

This instance of mental rudeness comes from among tribes who are hardly above the savage level, but not less remarkable survivals of primitive thought may be found among peasants. Thus that most archaic practice, the burial of objects for the use of the dead in the future life, is still continued in Europe. One of the latest instances comes from the village of Lückendorf in Saxony, where the schoolmaster, Herr Kühne, describes how when a mother dies in childbirth, they bury in the coffin all she wants for the child gone before-the little earthen pipkin and spoon, and a supply of groats, the baby-clothes, with needle and thread, thimble and scissors to mend them, and even a tiny model of the mangle, 
because it is too large to bury. This is in a Wendish district, where prehistoric customs are more obstinately kept up than in purely German parts. Nothing could more perfectly illustrate the early animistic belief in the ghost turning to ghostly use the phantoms of objects laid for it in the grave. Thus we have, parallel with the rude material life of the Stone Age, traces of a corresponding intellectual rudeness, belonging to ages when men had not learnt to distinguish dreams from events, or to realise the meaning of death.

The problem of the order in which the races of men were formed and attained such culture as they have is obscure and perplexed enough, but it has some illuminating facts. The method by which an anthropologist judges of the centre of civilisation of a race is much the same as that of the botanist who looks for the district where a widespread cultivated plant is found wild, as the potato is in Chile, which accordingly he takes to be at or near the centre of distribution; only he has to guard against the possibility of the wild plant being only a cultivated variety run wild. Let us now apply this method to the geography of the Negro race. The negro or negroid spread over the African continent have never risen high in civilisation, scarcely of themselves getting beyond the barbaric stage. But on the other hand they are never very low ; they are tillers of the soil, herdsmen, ironworkers, and no negroid tribe has been found in a clearly primitive savage state. The Bushmen, belonging to an allied variety of man, are outcasts and savages by degradation. If however we look along the map of the world for the eastern branch of the black race, we find in the Andaman Islands and in New Guinea and other islands Negro types more or less assimilated to the African, but living at lower stages of culture such as are possible in the rank forest-lands of the equator. In these two districts are found the only well-authenticated accounts of tribes with no knowledge of any means of making fire. The Andamanese have not the fire-drill or any such fire-making instrument, but carry burning brands about with them, and if by any chance they lost their fire, they could kindle it anew at their volcanoes. In an outlying district of New Guinea, Mikluho-Maclay bas found a Papuan tribe who only carry fire-brands, and do not know the fire-drill of other districts. This indicates very low culture, whether they are representatives of an originally fire!ess state, or whether by mere inertness they have disused and forgotten so useful an art as firemaking. In these regions is perhaps the Negro centre whence, rising to a somewhat higher level of culture, the western branch spread over Africa. Let us now look at the white men from this point of view. There may be remains of Stone Age Whites, but there are no certain remains of White savages of a low order. We may well doubt if there ever were any. White savages; it is more likely that the White men were developed late in the race-history of the world from ancestors allready far on in civilisation; in fact, that this civilisation with its improved supply of food, its better housing and clothing, its higher intellectuality, was one main factor in the development of the White type. Here, however, it must be remembered that there is not a White race in the sense in which there is a Carib race or an Andaman race. It includes several race-types, and even the same language, such as English or German, may be spoken by men as blond as Danes or as dark as Sicilians. The fair-haired Scandinavian type has something of the definiteness of a true race; but as one travels south there appear, not well-defined sub-races, but darkening gradations of bewildering complexity. The most reasonable attempt to solve this intricate problem is Prof. Huxley's view that the White race is made up of fair-whites of the Northern or Scandinavian type, and dark-whites who are the result of ages of mixture between the fair-whites and the darker nations, though it is perhaps hardly prudent to limit these dark ancestors to one variety as he does. If now we cannot trace the White man down to the low level or primitive savagery, neither can we assign to him the great upward movement by which the barbarian passed into civilisation. It is not to the Aryan of Persia nor to the Semite of Syria that the art of writing belongs which brought on the new era of culture. The Egyptian whose hieroglyphics may be traced passing from picture into alphabet had his race-allies in people of North Africa, especially the Berbers of the north coast, people whom no elasticity of ethnological system would bring into the white race. Of the race-type of the old Babylonians, who shaped likewise rude pictures into wedge-phonetic signs, we know but little as yet; at any rate their speech was not Aryan, and the comparisons of Lenormant and Sayce have given some ground for connecting it with the Turanian language, belonging to a group of nations of whom one, the Chinese, had in remote antiquity worked out a civilisation of which the development of an imperfect phonetic writing formed part. If the great middle move in culture was made, not by any branch of the white race, but by races now represented by the Egyptian and the Chinese, it is not less clear that these nations came to the limit of their developing power. The white races had in remote antiquity risen high in barbaric culture when their contact with the darker nations who invented writing opened to them new intellectual paths. The Greeks found in the ancient Egyptian theology the gods of the four elements, but they trans. ferred this thought from theology to philosophy, and developed from it the theory of elements and atoms which is the basis of modern chemistry. They found the Babylonians building terraced temples to the seven planets in the order of their periods, and this conception again they transferred from religion to science, founding on it the doctrine of planet-spheres which grew into mathematical astronomy. It may moderate our somewhat overweening estimate of our powers to remember that the white races cannot claim to be the original creators of literature and science, but from remote antiquity they began to show the combined power of acquiring and developing culture which has made them dominant among mankind.

\section{( $T o$ be continued.)}

\section{PROFESSOR ARTHUR ROCHE}

M. ARTHUR ROCHE, Professor of Mathematics and Astronomy at the Lycée of Montpellier, died at that town on April 18 last, in the sixty-third year of his age. M. Roche's name is most intimately associated with researches on the figures of planets and comets, and the cosmogonic theory of Laplace. In the report on the labours of Roche made to the Academy of Sciences last week by M. F. Tisserand, his memoirs were thus classified :- I. Various memoirs on the equilibrium of a homogeneous fluid mass subjected to certain conditions. These had special reference to the beautiful researches of mathematicians on the equilibrium of a homogeneous fluid mass, animated by a movement of rotation around its axis, the molecules of which are attracted according to the law of Newton. M. Roche proposed to determine the figure of equilibrium by taking into account a new force - the attraction exerted by a centre situated at a great distance. M. Roche worked out this idea with great success, applying it specially to the moon, to the satellites of Jupiter and Saturn, to comets, and generally to the evolution of the solar system. 2. Memoirs on the physical constitution of the terrestrial globe, in which he came to the conclusion that the density at the centre is nearly double the mean density. 3. Memoirs on the internal condition of the globe, in which $M$. Roche was led to pronounce against the complete fluidity of the interior. 4. Various memoirs on the figures of comets. 